\title{
The Risks of Autonomy: Empirical Evidence for the Necessity of a Balance Management in Promoting Organizational Innovativeness
}

\section{Diether Gebert, Sabine Boerner and Ralf Lanwehr}

For the purpose of promoting innovativeness in organizations, the literature recommends more decentralization of power and more participative leadership as one dimension of empowerment and thus greater situation control for employees. In fact, however, increasing situation control involves specific risks (including co-ordination problems). Without concurrent integration to cushion these risks through orientation, consensus and trust, increasing situation control therefore leads not to a further increase in innovativeness but to a decline. This first empirical demonstration of the covert curvilinear relationship between situation control and innovativeness in $\mathbf{n}=\mathbf{1 0 1}$ organizations reveals these risks. At the same time, it calls into question the widespread recommendations in the literature for action on innovation-friendly organization and leadership.

\section{The Issue}

$\mathbf{T}$ here is broad agreement in the literature that innovative organizations tend to be decentralized, to grant employees more decision-making autonomy, and to be characterized by delegatory and participative leadership (Axtell et al., 2000; Damanpour, 1991 p. 581; Glynn, 1996, p. 1102). Innovative organizations thus exhibit attributes of empowerment (Hardy \& Leiba-O'Sullivan, 1998, S463) that Burns and Stalker (1961) have identified as aspects of the "organic" organization.

Common to the organizational and leadership principles which the literature claims to be important for innovativeness - decentralized self-regulation, the decentralization of decision-making powers, the promotion of decision-making autonomy, the delegation of complex tasks and corresponding decisionmaking rights, and participative leadership is that situation control by the led increases. The degree to which employees can shape and influence matters increases. They have the opportunity to try out changes or innovations independently within their areas of responsibility. If they are led participatively, they can also influence their superiors and thus initiate projects for change. To this extent, the following theoretical reflections and empirical findings on the construct situation control are significant both for organizational and leadership studies.

Despite repeated reports of inconsistencies in the empirical relationship between variants of increasing situation control and organizational innovativeness (Fiol, 1996, p. 1013f.; Wolfe, 1994, p. 424), greater situation control is generally recommended to increase innovativeness, thus taking the linearity premise for granted: the more situation control, the more innovativeness.

We confront this recommendation with the thesis that an increase in situation control systematically causes specific unplanned negative secondary effects (Gebert \& Boerner, 1999), which not only impede but frustrate any further growth in innovativeness unless the organization cushions the unplanned negative 
secondary effects with an appropriate counterstrategy (integration). According to this thesis, the relationship between situation control and innovativeness is only apparently linear but in fact curvilinear. Curvilinearity, as opposed to linearity, means a specific inverted $\mathrm{U}$ relationship between situation control and innovativeness (in mathematical terms, a second-degree polynomial with negatively weighted quadratic term).

It is obvious that proof of covert curvilinearity would have far-reaching consequences. From a practical point of view, the usual recommendations to increase situation control would be problematic, since they underestimate the risk of advising this procedure without specific proposals on how to absorb these risks systematically. From a methodological point of view, for example, bivariate analyses could misjudge how close the relationship between situation control and innovativeness is because of the failure to take into account that the organization concurrently uses strategies to absorb these risks. Furthermore, quadratic functions would be needed as the basis for determining inverted $\mathrm{U}$ relationships statistically. And from a theoretical point of view, any description of conditions for enhancing innovativeness would be incomplete and misleading if theory takes no explicit account of the risks of extending situation control.

Against this background, we argue in detail the thesis of a covert curvilinear relationship between increasing situation control and innovativeness. On a theoretical basis we explain why innovation-related initiatives can be expected to multiply with an increase in situation control, but that specific unplanned negative secondary effects also arise. It is also explained why the postulated risks of increasing situation control can be cushioned by a specifically defined counter-strategy of integration. We go on to test empirically the assumption of a covert curvilinear relationship between situation control and innovativeness and the associated thesis of the buffer effect of integration. Conclusions are drawn for the promotion of organizational innovations.

\section{Theory \\ Innovation-Friendly Effects of Situation Control}

By innovativeness we mean the capacity of an organization to improve existing products and/or processes (Glynn, 1996, p. 1095), and the capacity to utilize the creativity resources of the organization to the full. We regard innovativeness, thus defined at the aggregate level of the organization, as a function of the innovation-related initiatives of employees implemented per unit of time in the organization. The implementation rate is, among other things, a function of the situation control of employees.

Situation control means the degree of perceived susceptibility of a situation to change, i.e. the extent to which members of the organization believe they can contribute directly by their own action or indirectly by actualizing the resources of others to the innovative improvement of the situation.

Situation control and innovativeness are linked theoretically in a model formulated by Gebert (1987) and empirically tested by Boerner (1998), which is based on Lazarus' (1991) stress management theory. We examine the relationship between situation control and innovativeness in the first place at the disaggregated level of the individual. We assume that a double process of appraisal precedes any innovative initiative on the part of employees.

Any action with the aim of innovative improvement presupposes both that a need for change in the situation is recognized and that a susceptibility to change is perceived (Gebert, 1987). The first evaluative process is concerned with the need for change. A situation is categorized as needing change when employees perceive a discrepancy between aspirations and actuality in the corporate situation. The measure of this discrepancy therefore determines the degree to which change is needed and, thus, the perceived need for innovative initiative. If no need for change is perceived, employees develop no innovative initiative.

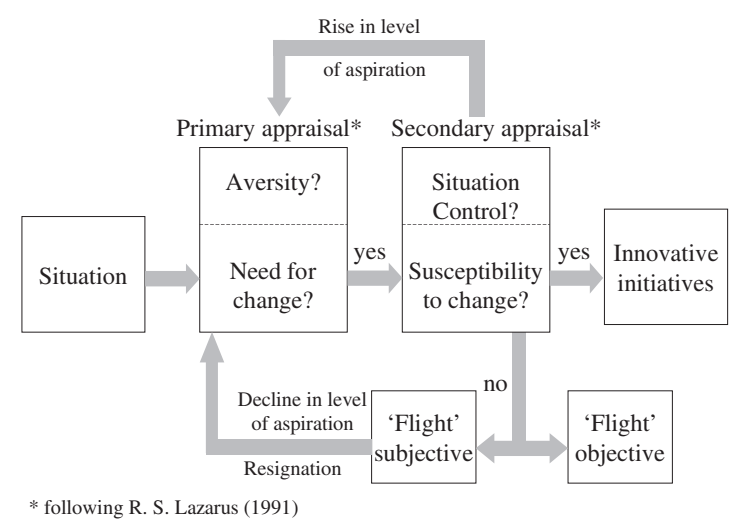

Figure 1. Situation Control as Catalyst for Innovativeness 
Where a need for change is seen (actuality $<$ aspirations), the controllability of the situation is examined in a second process of appraisal. If sufficient situation control is detected, the person concerned develops innovative initiative in the hope of improving the situation that needs to be changed. For this reason we assume a positive relationship between the degree of situation control and the number of innovative initiatives.

If a need for change is established in the course of primary appraisal, but secondary appraisal judges the situation not susceptible to change, and if the person concerned cannot objectively withdraw from the situation, resignative adaptation occurs. The demands made of the situation by the employee are lowered, and/or the actual position is upgraded by embellishment. The original aspiration/ actuality discrepancy is thus subjectively reduced, so that, as a result of this reappraisal, the situation is no longer perceived as needing to be changed. In this constellation it is likely that no initiative for innovation will be forthcoming from employees. An additional risk of resignative adaptation processes lies in their generalization to fields where change is possible and desired.

For many innovations, decisions on experiments and test runs in the context of organizational learning about, for example, the generation of new if-then rules (Cheng and Van de Ven, 1999, p. 606), cannot be decentralized but have to be made centrally. In this case it is crucial for employees to be able to communicate perceived needs for change up the hierarchy with subjective and objective prospects of success, so that, at least indirectly (by actualizing executive resources) they can categorize the situation as susceptible to change. This is one of the theoretical values of participative leadership: it raises the subjective probability of desired changes being feasible. The vertical communication thus encouraged, which makes tacit knowledge public and, in the sense of organizational learning, available for further processing by others, is repeatedly stressed as a significant factor for innovativeness (Cohen \& Levinthal, 1990; Glynn, 1996, p. 1103; Lam, 2000, p. 491).

It can thus be argued that increasing situation control for the members of an organization promotes its innovativeness because resignative adaptation processes are avoided and innovation-friendly initiatives on the part of organization members are enabled (Axtell et al., 2000, p. 274), which constitute the raw material for later innovation at the level of the organization.
Negative Secondary Effects of Greater Situation Control

In the wake of increased situation control, however, unplanned negative secondary effects are to be expected (Dougherty, 1996). These effects ultimately mean that, although there are more innovative initiatives, the implementation rate falls (see Figure 2) if the unplanned negative secondary effects are not appropriately cushioned.

If the situation is increasingly perceived as susceptible to change, employee aspirations generally grow relative to existing corporate practices. Expectations are raised and the value of the current position lowered. As the perceived susceptibility to change increases, so does the potential for criticism (lowering the value of the current position) because characteristics of the existing situation are interpreted less and less as being subject to material constraints (Gebert, 1987). On the other hand, aspirations grow because, the situation being perceived as susceptible to change, the search for alternative aspirations (for example, by comparison with other situations in other companies) is activated. This process of raising the aspiration level can with reference to Figure 1 - be interpreted as positive feedback from the process of secondary appraisal to that of primary appraisal (Lazarus, 1991). If a situation is perceived as susceptible to change, there is a greater tendency to perceive it as needing change. Raising the level of aspiration thus mirrors the decline in the level of aspiration described above (see Figure 1).

However, as a result of this rise in the level of aspiration (lowering the value of the current position and raising the level of expectations), which are in principle to be seen as favourable from the point of view of activating initiative, the following three unplanned negative secondary effects occur:

- Dysfunctional qualitative orientation of innovative initiatives. Reflecting a higher level of aspiration, the number of innovation-related initiatives that are not constructive and therefore not worth implementing increases with the rise in the absolute number of initiatives for change originated by employees.

- Dysfunctional intensity of innovative initiatives. The time and energy spent seeking compromises on innovations is generally experienced as less fascinating than achieving "absolute, resolute" solutions. An increase in situation control in the sense of a expansion of aspirations therefore often generates "everything-or-nothing" and 


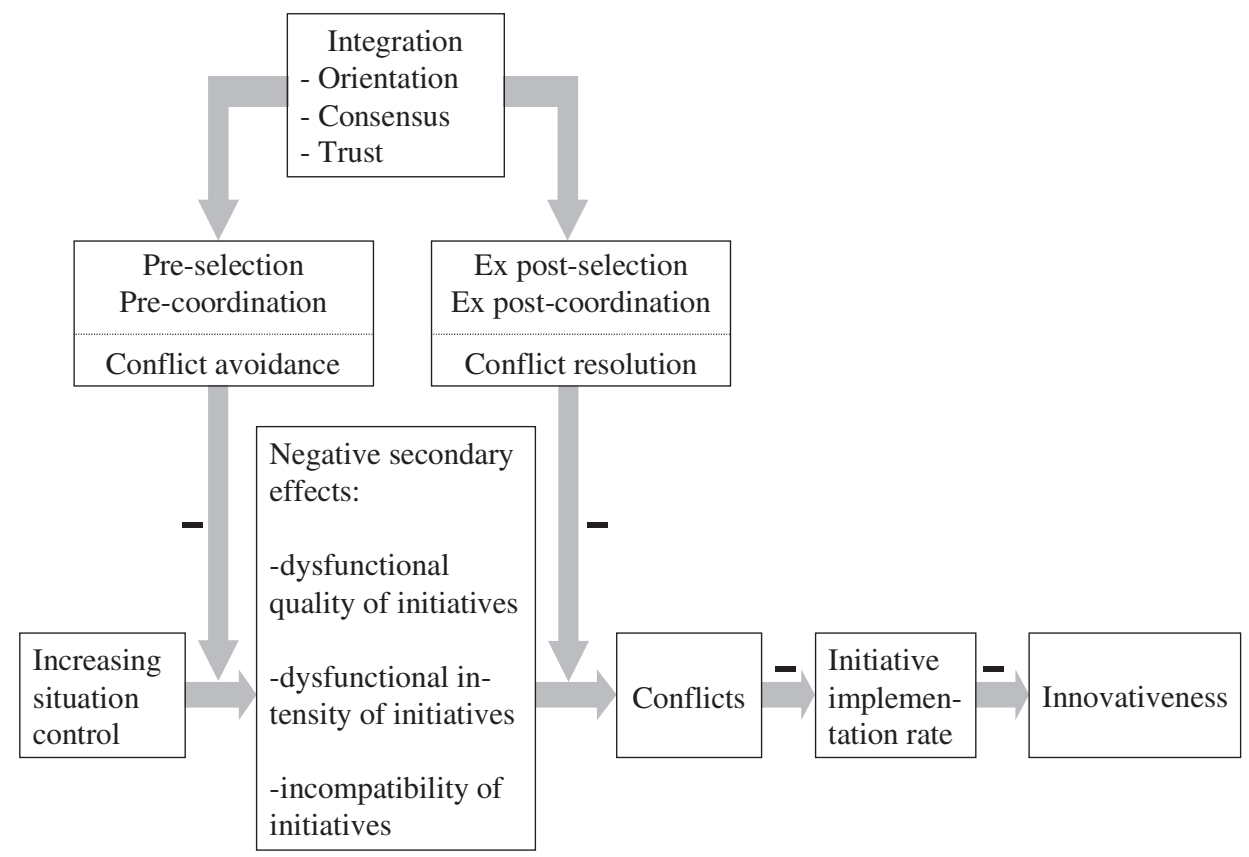

Figure 2. Negative Secondary Effects of Greater Situation Control on Innovativeness and their Compensation by Integration

"now-or-never" attitudes in practice, which tend to give rise to a more radical push for change (Gebert, 1987).

- Dysfunctional incompatibility of innovation-related initiatives. Augmenting situation control involves the risk of inadequate co-ordination in substance and timing between various innovative initiatives being tested independently by decisionmakers in their respective functional areas. This risk is discussed in the literature under the heading "autonomy costs of decentralization".

All three effects (dysfunctional qualitative orientation, dysfunctional intensity, and dysfunctional incompatibility of innovationrelated initiatives) imply that with increasing situation control not only the number of constructive innovation-related initiatives increases but also the number of those that put the goal in jeopardy. If detrimental initiatives outweigh constructive initiatives, the implementation rate declines. The generation of this constellation can be explained as follows.

The three negative secondary effects imply subsequent decisions on the modification or rejection of innovation-related initiatives. These decisions require clear selection criteria. Since the existence of such selection criteria cannot be taken for granted, decisions about modification or rejection can lead to conflict, not least of all because these decisions disappoint the people who have developed the initiatives. Since, although substantive conflicts can be analytically distinguished from relational conflicts, they frequently re-inforce each other, disputes can be expected to escalate (Jehn, 1995, p. 268). As conflict escalates, even selection criteria that may so far have been respected become less acceptable and binding. The growing void is increasingly filled by the exercise of power and micropolicy (Burns \& Stalker, 1961). This increases the danger of constructive innovation-related initiatives being rejected and detrimental initiatives being accepted: the implementation rate falls.

Increasing situation control thus proves a Janus-faced strategy, since the unplanned negative "secondary effects" trigger processes that displace the positive "primary effects". If such a development is to be avoided, innovation-friendly conflict avoidance and resolution are needed (see Figure 2). This is the purpose of the compensatory counter-strategy of integration.

\section{Integration as Compensation of Negative Secondary Effects}

We assume that the negative secondary effects of situation control can be compensated by integration. We understand the construct integration to include cognitive and evaluativeaffective aspects. The cognitive aspect of integration ('orientation') is concerned with 
the clarity of the organization's strategic course (clear objectives in basic issues and organizational policy). The evaluativeaffective aspect of integration is concerned with the degree to which the organization's strategic course is shared by all ('consensus'), and is thus approved. Second, the evaluativeaffective aspect is concerned with the degree to which mutual confidence ('trust') arises as an expression of a clear, shared strategic course (in the sense of a positive sum game), and people consequently feel themselves to be emotionally integrated. These aspects thus merely reflect the same construct ('integration') from different angles. We now explain the compensatory effects of integration as thus defined.

In the first place, integration supports the processes of pre-selecting and pre-coordinating innovation-related initiatives, which serve conflict avoidance.

(a) Orientation, defined in terms of the clarity of the strategic course set by the organization, is one aspect of integration. The clarity of course determines the direction and cognitive scope for potential innovation-related initiatives, thus setting cognitive limits to the process of developing initiatives. In the knowledge of the long-term organizational course, the pre-selection of innovative initiatives is more purposive, more moderate and better co-ordinated.

Additionally needed interpersonal pre-coordination is also facilitated by the evaluativeaffective aspects of integration ('consensus' and 'trust').

(b) We define consensus as the capacity to reach agreement within the organization on fundamental issues. Consensus obviates debates on principles when specific innovative initiatives are to be modified in the course of pre-coordination.

(c) We define trust as mutual willingness to accept vulnerability (even without contractual protection). Trust reflects the experience of mutual fairness and reliability (Rousseau et al., 1998, p. 401). In the context of positive-sum games, this experience reduces the likelihood of micro-political intentions being mutually imputed in the course of pre-coordination when changes in innovative initiatives are under discussion.

By fostering pre-selection and precoordination, integration thus contributes to the following effect: the number of dysfunctional innovation-related initiatives for change declines, so that the rate of successfully innovation implementation rises.

But integration is needed for another reason, too. Even when orientation, consensus and trust are highly developed, the quantity of detrimental innovation-related initiatives is not reduced to zero. This is impossible if only because, although the cognitive scope for innovation-related initiatives defined by orientation is limited, it nevertheless remains subject to interpretation and, to a certain extent, ambiguous.

For this reason, too, not only pre-selection and pre-coordination are needed in practice, but also ex-post-selection and ex-post-coordination as well as appropriate conflict resolution when specific innovation-related initiatives need to be rejected or changed. Keeping in mind the reasons we have given for why the rate of successfully implemented initiatives declines in the face of inevitable subsequent decisions on modifying or rejecting innovative initiatives, it is clear that the counter-strategy of integration favours the implementation rate because it promotes conflict settlement.

As integration intensifies, the unplanned negative effects of increasing situation control are effectively cushioned by conflict avoidance and later conflict resolution. However, this means that without such compensation, an organization can find itself in difficulties that can substantially jeopardize innovativeness. This is obviously also realized by consultants and companies (Hardy \& Leiba-O'Sullivan, 1998 , p. 463). This explains why on the one hand they advocate empowerment and entrepreneurship (corresponding to increasing situation control) while nevertheless stressing visionary leadership and the importance of trust in the organization (corresponding to increasing integration). If renowned businesses embrace such practices, they are emulated by other companies (Greenwood \& Hinings, 1996, p. 1028), so that the compensatory strategy of integration is more broadly diffused.

For this reason we expect the degree of situation control in organizations to be positively linked with the degree of integration. Organizations that take no compensatory measures to counter increasing situation control would, according to this approach, run the risk of losing their innovativeness and thus their competitiveness. Finally, we assume that, because of the concurrent integration processes, the empirical observer gains the impression that the innovativeness of an organization grows as situation control increases (in terms of the linearity thesis). If, in contrast, the degree of integration were to be kept constant, it should be apparent that, in 
keeping with the curvilinear thesis, innovativeness declines from a certain level of situation control.

The hypothesis to be tested is as follows. If integration is held constant, situation control and innovativeness exhibit an (inverted $\mathrm{U}$ ) curvilinear relationship; if integration is concurrent, the relationship is linear.

\section{Empirical Study}

\section{Measurement}

The construct situation control embedded in the theory shown in Figure 1 was operationalized with the following items (the data were collected in standardized form on a five-point scale: "strongly agree", "agree", "uncertain", "disagree", "strongly disagree").

- In this company employees have the feeling they can discuss even fundamental company practices with management (S1).

- We have learned that you can elude material constraints (S2).

- Employees here think a lot needs to be changed, but that change is impossible (recoded) (S3).

- We've come to the conclusion that practically everything can be done otherwise (S4).

- The success of this company is attributed mainly to the ability to get things moving and to bring about change actively (S5).

- In our experience, you can generally achieve more in this organization that it would seem at first (S6).

The construct integration (consensus, orientation, trust) as defined above was operationalized with three items:

(a) Orientation $(\mathrm{O})$

- Many feel a lack of reliable orientation on fundamental issues (recoded) (O1).

- The top-management in this organization always succeed in giving employees a clear basic orientation (O2).

- Even if a person is sometimes at a loss on details, the general direction of the task is clear (O3).

(b) Consensus (C)

- In our organization, everyone pulls together. There is no quarrelling that could seriously endanger unity (C1).

- Conflicts about the matter itself seldom end in protracted debates on principles (C2).

(c) Trust (T)

- In our organization people can show their weaknesses without it being used against them (T1).
- We're very far from being a trusting organization (recoded) (T2).

- Without backing from your superior noone here takes a risk (recoded) (T3).

In operationalizing innovativeness we set the following seven questions concerning comparison with competitors, comparison with own past innovativeness and comparison between the innovativeness attained and own innovative potential. As we see it, only the combination of these three aspects permits a valid measurement of innovativeness; taking only one of the three measures into account gives a one-sided and thus less valid picture.

- With regard to innovativeness (e.g. creativity, new products, new processes), is your company or the division you are assessing better, just as good or worse than its competitors? (I1)

- In your opinion, is the available potential for innovativeness/creativity fully exploited in your company (to a low degree, partly, to a high degree)? (I2)

- Over the past three years, has your company been better, just as good or worse than before as regards innovativeness (e.g. creativity, new products, new processes)? (I3)

- If we want to be as innovative as our best competitor, we still have a long way to go (recoded) (I4).

- The last innovation in our organization that was really important for the success of the company was years ago (recoded) (I5).

- Our company has a reputation among internal/external customers for creative, innovative problem-solving (I6).

- Crucial innovation/creativity resources lies fallow in this organization (recoded) (I7).

With regard to the reliability of measurement of the three constructs situation control, integration and innovativeness the following results emerged, as shown in Table 1.

On the basis of these three reliable scales, the six items on situation control are summated under the heading "situation control", the eight items on integration under "integration" and the seven items on innovativeness under "innovativeness".

\section{Sample}

In this study the number of respondents corresponds to the number of organizations or organizations units under investigation $(\mathrm{n}=$ 101). In contrast to studies in which respondents are recruited from only a few organizations, variance in this investigation is organizational rather than personal. Only 
Table 1. Reliabilities (Cronbach's $\alpha$ ) of the Measured Constructs

\begin{tabular}{lll}
\hline Construct & $\begin{array}{l}\text { No of } \\
\text { items }\end{array}$ & \\
\hline
\end{tabular}

\begin{tabular}{lll}
\hline Situation Control & 6 & 0.758 \\
Integration & 8 & 0.808 \\
Innovativeness & 7 & 0.901 \\
\hline
\end{tabular}

executives were interviewed (mostly departmental managers). We approached the randomly selected respondents personally; presumably as a result of this personal contact, the response rate was $65 \%$.

The 101 organizations or organizational sub-systems were recruited in the service sector (insurance, banking, consultancy, media) and manufacturing (motor vehicles, chemicals, electric and electronic equipment, mechanical engineering).

\section{Results}

Table 2 shows correlations between the three central variables situation control, integration, and innovativeness.

All three variables show significant positive inter-correlation. In substance, our central thesis is that the relationship between situation control and innovativeness takes the covert curvilinear form of an inverted $U$, while appearing to be linear because concurrent integration cushions the unplanned negative secondary effects of a higher measure of situation control.

If one wished to reveal the risks of a marked and one-sided increase in situation control (i.e. the potential inverted $U$ form of the relationship between situation control and innovativeness), integration processes covariant with situation control that cushion the negative secondary effects of situation control must be controlled for and their effect eliminated in computing the correlation between situation control and innovativeness. If the level of integration is kept constant, the risks of increasing situation control (and thus the posited covert curvilinearity) would have to be apparent. The results of this test are shown in Table 3.

If, after controlling for the effect of integration, we take the inverted $U$ function - a quadratic function - as the basis, the quadratic term is significant, as Table 3 shows. This means nothing other than that, after controlling for integration, the function between situation control and innovativeness does not rise in
Table 2. Correlation Coefficients between

Situation Control, Integration and

Innovativeness

Innovativeness Integration

\begin{tabular}{lll}
\hline Situation & $0.639^{* * *}$ & $0.591^{* * *}$ \\
Control & $(\mathrm{n}=95)$ & $(\mathrm{n}=97)$ \\
Integration & $0.634^{* * *}$ & \\
& $(\mathrm{n}=93)$ & \\
\end{tabular}

***: significant for $\mathrm{p}<0.001$.

Table 3. Regression Coefficients ( $\beta$ ) of Situation Control on Innovativeness after Controlling for the Impact of Integration

\begin{tabular}{lll}
\hline $\mathbf{R}$ & $\boldsymbol{\beta}_{\text {Linear }}$ & $\boldsymbol{\beta}_{\text {Quadratic }}$ \\
\hline $0.409^{* * *}$ & $0.358^{* * *}$ & $-0.244^{*}$
\end{tabular}

*: significant for $p<0.05$; ${ }^{* *}$ : significant for $\mathrm{p}<0.001$

constant linearity but reaches a maximum beyond which it falls again. Precisely this finding confirms our central hypothesis (see Figure 3).

\section{Conclusions}

The successful demonstration of covert curvilinearity has a number of implications. Since the frequently recommended procedures of decentralized self-regulation, decentralization of decision-making powers, the promotion of decision-making autonomy and empowerment as well as participative leadership imply an increase in situation control, they are associated not only with opportunities but also with identifiable risks (hitherto little discussed in the literature).

With regard to innovativeness, there can be not only too little situation control but, where not absorbed, too much. Burns and Stalker (1961) have warned against absolutizing the strategies of decentralized self-regulation, the promotion of decision-making autonomy and so on, although their terminology differs. At the practical level, solving this problem by dosing situation control proves very difficult. Since there is no clear yardstick for situation control and the optimum is unknown ex ante, practitioners can often act only ex post, when 


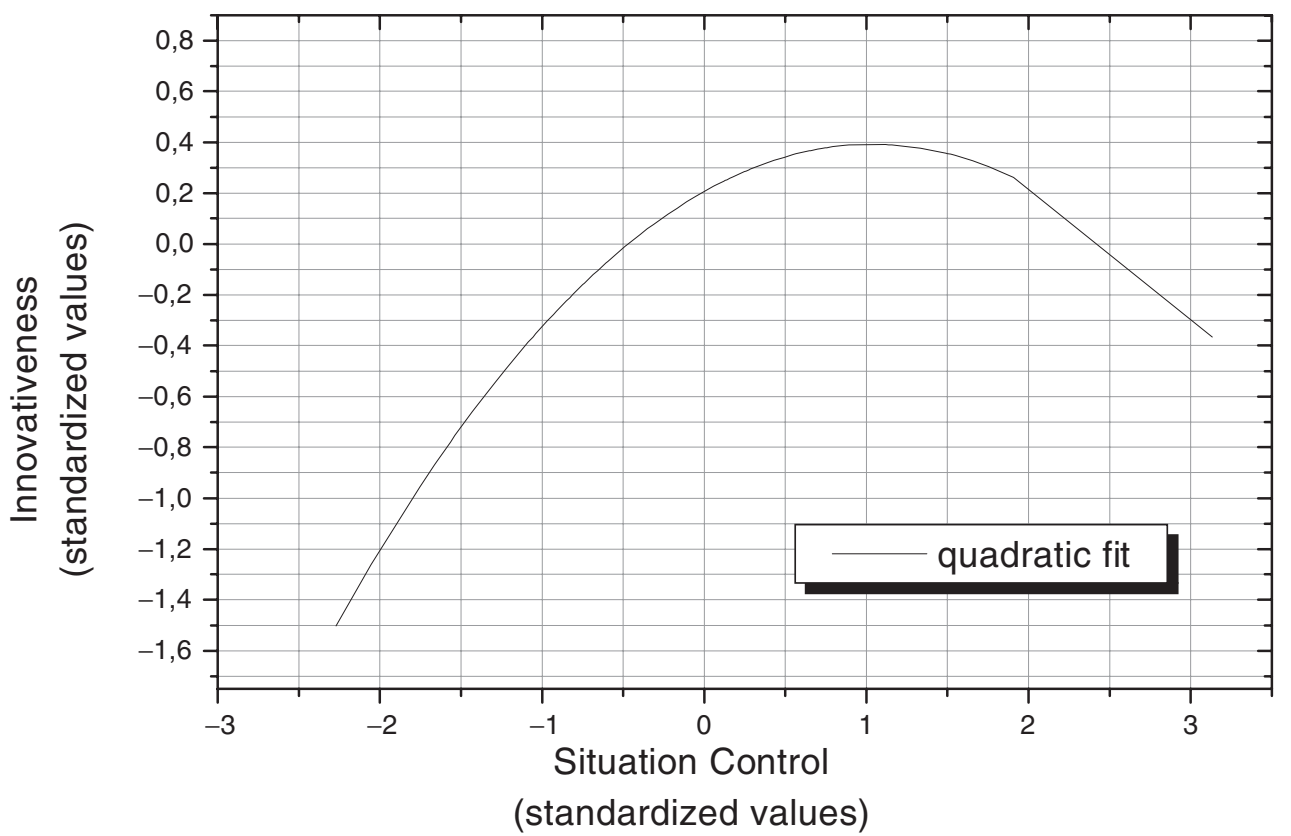

Figure 3. Relationship between Situation Control and Innovativeness (Controlling for the Effects of Integration)

innovative initiatives either peter out or develop into prospectively uncontrollable destabilization of the organization. Not infrequently, an everything-or-nothing attitude and now-or-never thinking arise as well, especially among younger employees, with the result that members of the organizations are not to be satisfied with gradual increases in situation control.

To this extent a strategy of compensation is preferable to one of dosing. The promotion of orientation, consensus and trust seems to be the counterweight that prevents the actuation of initiatives and change from veering into conflict escalation and paralysis. Under these conditions the relationship between situation control and innovativeness is in fact linear and does not merely appear to be linear, so that innovativeness does not begin to decline with increasing situation control but continues to rise.

From a practical point of view, transformational leadership, operationalized in accordance with Avolio, Bass and Jung (1999), is relevant in this context (Keller, 1992). The trust bonus of leaders vis-à-vis the led allows a potential for trust to develop; an inspiring common vision enables orientation and builds a potential for consensus. In this way the risk of increasing situation control through delegation and participation can be cushioned.

As we have seen, companies tend to favour this buffer strategy. Nevertheless, the need for it must be stressed: as our empirical analysis has shown, there are companies that do not consistently practice such compensation. Moreover, it is important for practical reasons to describe and justify the content of the strategy more precisely to permit more effective action.

\section{References}

Avolio, B.J., Bass, B.M. \& Jung, D.I. (1999) Reexamining the components of transformational and transactional leadership using the multifactor leadership questionnaire. Journal of Ocсupational and Organizational Psychology, 72, 441-462.

Axtell, C.M., Holman, D.J., Unsworth, K.L., Wall, T.D. \& Waterson, P.E. (2000) Shopfloor innovation: Facilitating the suggestion and implementation of ideas. Journal of Occupational and Organizational Psychology, 73, 265-285.

Boerner, S. (1998) Work alienation and continuous improvement. In Boer, H. \& Gieskes, J. (eds.), Continuous improvement - From idea to reality, Twente University Press, Enschede, pp. 63-75.

Burns, T. \& Stalker G.M. (1961) The management of innovation. Tavistock, London.

Cheng, Y.T. \& Van de Ven, A.H. (1996) Learning the innovation journey: Order out of chaos?. Organization Science, 7(6), 593-614.

Cohen, W.M. \& Levinthal, D.A. (1990) Absorptive capacity: A new perspective on learning and innovation. Administrative Science Quarterly, 35, 128-152.

Damanpour, F. (1991) Organizational innovation: A meta-analysis of effect of determinants and 
moderators. Academy of Management Review, 34(3), 555-590.

Dougherty, D. (1996) Organizing for innovation. In Clegg, S. R., Hardy, C. \& Nord, W.R. (eds.), Handbook of organization studies. Sage Publications, London, pp. 425-439.

Fiol, C.M. (1996) Squeezing harder doesn't always work: Continuing the search for consistency in innovation research. The Academy of Management Review, 21(4), 1012-1021.

Gebert, D. (1987) Führung und Innovation [Leadership and Innovation]. Zeitschrift für betriebswirtschaftliche Forschung, 39(10), 941951.

Gebert, D. \& Boerner, S. (1999) The open and the closed corporation as conflicting forms of organization. The Journal of Applied Behavioral Science, 35(3), 341-359.

Glynn, M.A. (1996) Innovative genius: A framework for relating individual and organizational intelligences to innovation. The Academy of Management Review, 21(4), 1081-1111.

Greenwood, R. \& Hinings, C.R. (1996) Understanding radical organizational change: Bringing together the old and new institutionalism. The Academy of Management Review, 21(4), 10221054.

Hardy, C. \& Leiba-O'Sullivan, S. (1998) The power behind empowerment: Implications for research practice. Human Relations, 51(4), 451-483.

Jehn, K.A. (1995) A Multimethod Examination of the Benefits and Detriments of Intragroup Conflict. Administrative Science Quarterly, 40(2), 256-282.

Keller, R.T. (1992) Transformational Leadership and the Performance of Research and development project groups. Journal of Management, 18(3), 489-501.
Lam, A. (2000) Tacit knowledge, organizational learning and societal institutions: An integrated framework. Organization Studies, 21(3), 487-514.

Lazarus, R.S. (1991) Emotion and adaptation. Oxford University Press, New York.

Rousseau, D., Sitkin, S.B., Burt, R.S. \& Camerer, C. (1998) Not so Different After All: A crossdiscipline view of trust. The Academy of Management Review, 23(3), 393-404.

Van de Ven, A.H. (1999) Central Problems in the Management of Innovation. Management Science, 32(5), 590-617.

Wolfe, B. (1994) Organizational innovation: Review, critique and suggested research directions. Journal of Management Studies, 31, 405-431.

Prof. Dr. Diether Gebert is at the Berlin Technical University, Faculty of Economics, and Management, Department of Human Resource Management, 10585 Berlin Wilmersdorfer Str. 148, Germany, phone (030) 31423234.

Prof. Dr. Sabine Boerner is at the Lahr School of Economics, Department of Human Resource Management and Intercultural Management, Hohbergweg 15-17, 77933 Lahr

Germany, phone (07821) 9238-59. e-mail: s.boerner@akad.de

Ralf Lanwehr is at the Berlin Technical University, Faculty of Economics and Management, Department of Human Resource Management, 10585 Berlin, Wilmersdorfer Str. 148 Germany, phone (030) 31423234. 